\title{
Synthesis of Novel Biodegradable Quaternary Amine-based Cross-linked Poly( $\beta$-amino ester) and Its Self-assembly/disassembly with Plasmid DNA
}

\author{
Tae-il Kim, Hyo Jung Seo, Jung-ın Baek, Jae-Hun Park," and Jong-Sang Park" \\ School of Chemistry \& Molecular Engineering. Seoul National Linersity, Seoul $151-7+2$, Korea \\ "E-mail: pfisparkíaplaza.snuac:kr \\ "Korean Minjok Leadership Academ, 1334 Sosa-lee, Anhung-myn. Hwoingsung-gun, Kangwon 225-823. Korea \\ Recened October 26, 2004
}

Key Words : Cross-linked polymer, Quaternary amine, Biodegradability, Gene delivery

In recent years, various eationic polymers constructed using ester bonds, phosphoester bonds or disulfide bonds have been synthesized to create environmentally-responsible biodegradable delivery systems, ${ }^{1-3}$ Among them, a crosslinked type polymeric gene delivery carrier was reported to show enlanced transfection efficiency due to its threedimensional structure leading endosome buffering effect. and self-assemble with plasmid DNA giving more stable polyplexes due to its slow degradation in acjueous media, in contrast to linear type carriers. ${ }^{4}$

Several quatemary amine-based polymeric gene delivery carriers were reported and they showed considerable gene delivery potencies. ${ }^{5-8}$ Morcover, a primary amine-based biodegradable polymeric carrier was known to have potentially rapid self-destructive tendency due to the attack of its own primary amines." Because quaternary amines have no nucleophilicity, quatemary amine-based biodegradable polymeric carriers have no possibility of 'self-destruction'. So, we designed a novel quaternary amine-based crosslinked poly ( $\beta$-amino ester) polymer (Q-Cl.PAF).

Here, we report the synthesis, characterization of $Q_{-}$ CL.PAF. In addition, the self-assembly of polymers with plasmid DNA and in vitro disassembly of plasmid DNA from polyplexes are presented.

Q-CI.PAГ was synthesized by using a Michael reaction of a quaternary amine monomer and a triacrylate monomer according to $\left[\right.$ ynn et al. ${ }^{10}$ First, a quaternized amine monomer was synthesized through the following steps (Scheme 1).
Fmoc blocking reaction of $\mathrm{N}, \mathrm{N}$-dimethylethylenediamine (DMFDA). Frnoc-OSu (1 g, $2.96 \mathrm{mmol}$, Novabiochem, laufelfingen, Switzerland) was dissolved in 1,4dioxane. DMГDA (0.488 ml., 4.45 mmol, Sigma-Aldrich, St. l.ouis, MO) was dissolved in 1,4-dioxane and added to an Fmoc-OSu solution dropwise, keeping it at r.t. overnight. Then, the reaction mixture was poured into diethyl ether and extracted with water to remove the residual DMFDA. The ether layer was extracted again with $0.1 \mathrm{M} \mathrm{HCl}$ solution. At this time, the acidified product was transferred to the $\mathrm{HCl}$ layer and the residual Fmoc-OSu was left in the ether layer. The HCl layer was basified to $\sim \mathrm{pH} 11$ with $1 \mathrm{~N} \mathrm{NaOH}$ solution and the hydrophobic product in the acjueous layer was extracted with diethyl ether. Finally, after evaporation of the ether latyer, a purified product, $\mathrm{N}-(9-\mathrm{F}$ luorenylmethoxycarbornyl)-N',N'-dimethylethylenediamine (Fmoc-DMEDA) was left as a white solid.

Methylation of Fmoc-DMEDA. Fmoc-DMГDA (195 $\mathrm{mg}, 0.598 \mathrm{mmol}$ ) was dissolved in DMF, $3.72 \mathrm{ml}$. of iodomethane ( $\mathrm{d}=2,28,59.8 \mathrm{mmol}$, Sigma-Aldrich) was added to an Fmoc-DMГDA solution, keeping it at r.t. overnight. The product was precipitated with diethyl ether three times to remove the unreacted materials, leaving a light yellow solid, N-(9-Fluorenylmethoxycarbornyl)-N', $N^{1} . N^{\prime}-$ trimethylethylenediamine ( $F$ moc-TMГDA).

Fmoc deblocking of Fmoc-TMEDA. Fmoc-TMEDA (101 mg, $0.296 \mathrm{mmol}$ ) was dissolved in DMF and mixed with an equal volume of $30 \%$ piperidine solution (DMF). After stirring at room temperature, the product was pre-

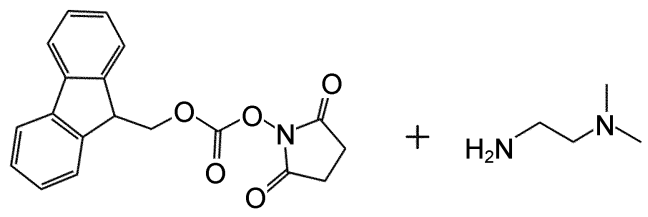

$\overrightarrow{\text { 1,4-dioxane }}$
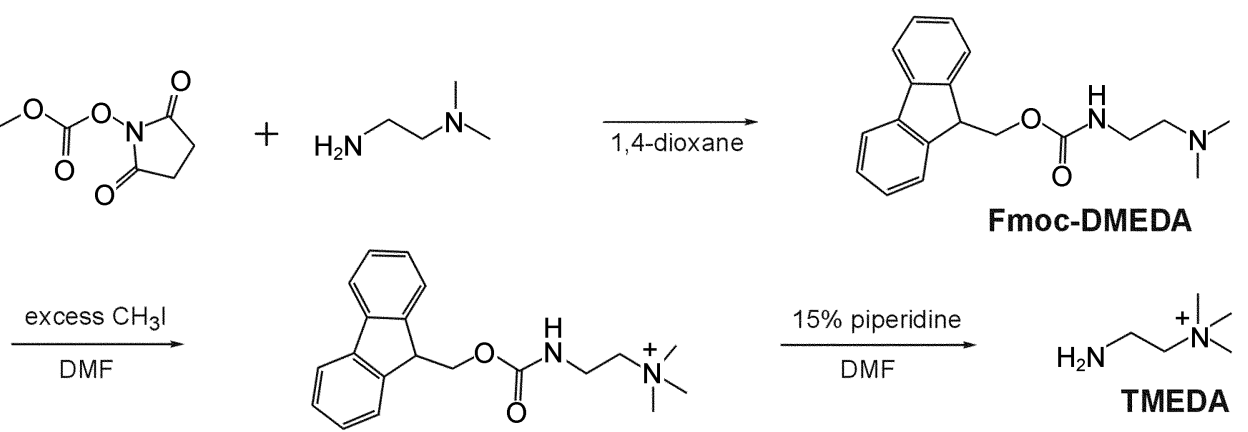

Fmoc-TMEDA

Scheme 1. Synthesis scheme ol quatemized amine monomer. 

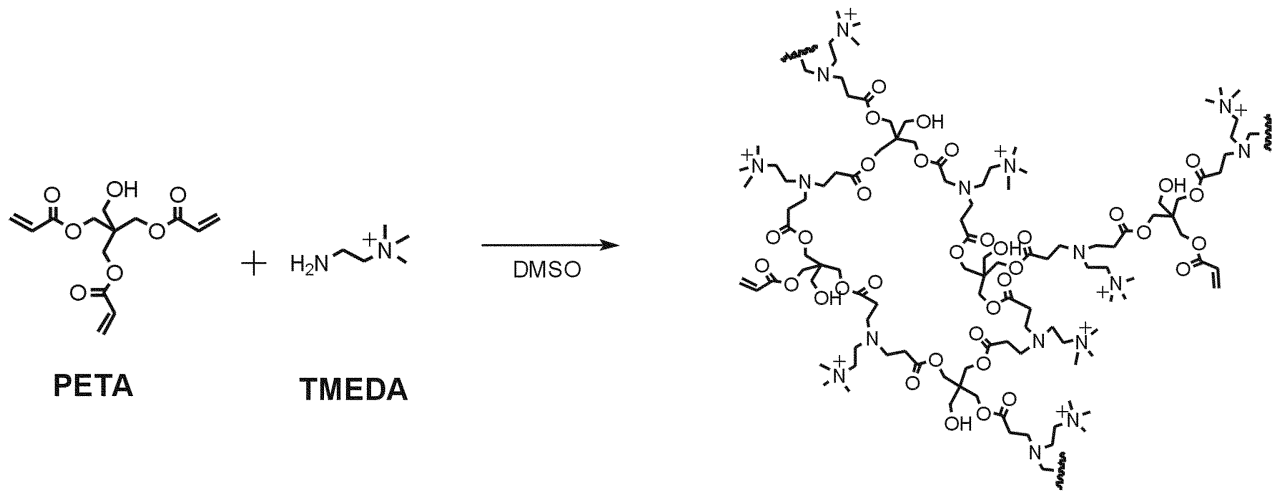

Q-CLPAE

Scheme 2. Synthesis scheme of Q-CLPAE.

Table 1. Average sizes $\left(Z_{\text {ace }}\right)$ and zeta-potentials of Q-CLPAE polyplexes. Measured values were presented as the average values of 5 runs

\begin{tabular}{cccccc}
\hline & Wr l & 2 & 5 & 10 & 20 \\
\hline$Z_{\text {are }}(\mathrm{nm})$ & $229.3+10.0$ & $106.1-5.4$ & $343.5-22.7$ & $293.6+13.2$ & $277.6+30.7$ \\
Zeta-potential $(\mathrm{mV})$ & $-29.3+0.1$ & $-13.2+1.6$ & $4.9+0.5$ & $20.1+0.3$ & $26.5-2.6$ \\
\hline
\end{tabular}

Wr: Weight ratio of the polyplexes

cipitated with cold diethyl ether to remove the residual piperidine, leaving a white solid. N.N,N-trimethylethylenediamine (IMEDA). All syntheses were confirmed by $300 \mathrm{MHz}{ }^{1} \mathrm{H}$ NMR (Bruker DPX-300)."

Then, Q-Cl.PAF polymerization was performed in DMSO (Scheme 2). 'IMEDA (18.1 $\mathrm{mg}, 0.173 \mathrm{mmol}$ ) and pentaerythritol triacrylate (PËlA, $25.9 \mathrm{mg}, 0.087 \mathrm{mınol}$, SigmaAldrich) were dissolved in DMSO. To synthesize crosslinked polymers, PE"IA was used as a trivalent linker and chosen because it had the shortest carbon backbone length among analogous acrylate monomers and so its polymer would possess the high charge density, which is known to generally lead to high transfection in cells. Moreover, it has a hydroxyl group, which would enhance the water solubility of the polymer. IMEDA solution was added to the triacrylate solution, keeping it at $50^{\circ} \mathrm{C}$. After 5 days, the reaction mixture was cooled to room temperature and evaporated under vacuum. The product was dissolved in DMF to separate the DMF-insoluble IMEDA and precipitated into diethyl ether 2 times, leaving a light yellow solid, Q-CLI'AE.

The average molecular weight of the polymer was determined by multi-angle laser light scattering (MALLS) in combination with size exclusion chromatography (SEC). ${ }^{12}$ The $\mathrm{M}_{\text {n }}$ of Q-CLPAE was measured to be $8.43 \times 10^{3} \mathrm{Da}$ $(\mathrm{PDI}=1.28, \mathrm{dn} / \mathrm{dc}=0.104)$.

The sizes of Q-CLI'AE polyplexes were measured by light scattering to confirm the self-assembly of Q-CLPAE with pCN-Luci plasmid DNA giving nano-sized polyplexes, and the zeta-potentials of each polyplex were determined at various weight ratios (lable 1). ${ }^{1.3}$ The average size of QCLPAE polyplexes was $344 \mathrm{~nm}$ at the weight ratio of 5 and decreased to $278 \mathrm{~nm}$ at 20 . Considering the zeta potential values of polyplexes together, Q-CLPAE was thought to self-assemble with plasmid DNA to form partially condensed and negatively charged polyplexes intermediate below the weight ratio of 5. Above the weight ratio of 5, Q-CLPAE showed that it could self-assemble with plasmid DNA to form positively charged and stable polyplexes in the size or zeta potential values.

In general, linear type cationic ester polymers were reported to be degraded in aqueous media within a few hours and be unable to self-assemble with plasmid DNA any longer. ${ }^{1 .}$ Considering the harsh in vivo condition including a fast blood stream. enzyme attack and low $\mathrm{pH}$, the stability of polyplexes is important for therapeutic purposes. Therefore, the disassembly pattern of plasmid DNA from Q-CLPAE polyplexes was examined by agarose gel retardation assay (Figure 1). ${ }^{14}$ The stability of Q-CLI'AE polyplexes increased with increasing weight ratio where the polyplex remained intact over 2 days at a weight ratio of 20 . We can conclude that the stability of Q-CLPAE polyplexes is enhanced compared to that of linear biodegradable polymer/DNA complexes.

In sumınary, biodegradable quaternary amine-based crosslinked poly( $\beta$-amino ester) (Q-CLPAL) was synthesized for

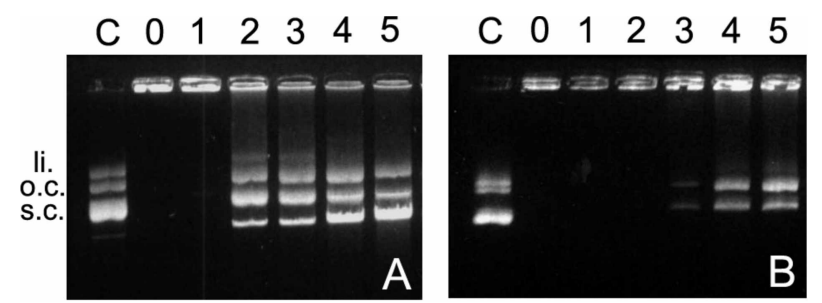

Figure 1. Gel Retardation assay. (A) weight ratio $=5$. (B) weight ratio-20. C: D.A only: خumbers represent the incubation days of the polyplexes. s.c. super coiled ISNA, o.c. open circular IDNA, $\mathrm{li}_{.}=$linear DN $\mathrm{A}$. 
gene delivery systent. Q-CLPAE is able to self-assemble with plasnid DNA to create positively charged stable polyplexes from the weight ratio of 5 . and the size of these polyplexes were estimated to be $278 \mathrm{~nm}$ at the weight ratio of 20. Fulfilling our expectations. Q-CLPAE polyplexes showed prolonged disassembly patterns with plasmid DNA and an increased stability of the polyplexes, which nay be due to cross-linked structure and non-nucleophilc quaternized amines of Q-CLPAE. Transfection assay and other cellbased experiments are in progress

Acknowledgments. We thank Hyung-suk Jang in Samsung Medical Center (Seoul, Korea) for providing pCN-Luci vector. This study was supported by the National R \& D Progran Grant of The Ministry of Science and Teclunology (M1031006007-03B+606-00710), the SRC-Molecular Therapy Research Center at Sungkyunkwan University (R11-2000-080-10003-0)(2004) and the Korea Institute of Science and Technology Evaluation and Planning (KISTEP) (Ml0310120001-03B4612-00110).

\section{References and Notes}

1. Lim. Y: Kim. C.: Kim. K.: Kim. S. W.: Park. J. J. Am. Chen. Soc. 2000, 122, 6524-6525.

2. Zhao, Z: Wang J: Mao, H: Leong. K. W. Ad. Drug Del. Rev: $2003,55,483-499$.

3. Gosselin. M. A.: Guo. W. Lee. R. J. Bioconjigate Chem. 2001. 12. $989-994$

4. Lim. Y: Kim. S.: Sul. H.: Park. J. Bioconjugate Chen. 2002. 13. $952-957$.

5. Lee, I. H.: Lim, Y: Choi, J. S.: Lee, Y: Kim. T: Kim, H. I.: Yoon. I. K: Kim. K: Park, I. Bioconjugate Chem. 2003. 1t. 1214-1221

6. Lee. J. H.: Lim. Y: Choi. J. S.: Choi. M.: Yang. C.: Park. J. Bull.
Korem Chem. Soc. 2003. 24. 1637-1640

7. Brownlie. A.: Uchegbu. I. F.: Schätzlein. A. G. Int. J. Phamt. 2004. 274. 41-52.

8. Reschel, T.: Konkák, C.: Oupicky. D.: Seymour. L. W.: Ulbrich, K. J. Connol Retease 2002, 81, 201-217.

9. Lim. Y.: Choi, Y. H.; Park, J. J. Am. Chem. Soc. 1999, 121, $5633-$ 5639.

10. Lytn1. D. M.: Langer. R. J. Am. Chent. Soc. 2000. 122. 1076110768

11. Fmoc-DMEDA $\left(\mathrm{CDCl}_{3}\right): \delta$ Fmoc (aromatic protons) $=7.26-7.78$; $\delta$ DMEDA $\left(-\mathrm{CONHC} \mathrm{H}_{2}-\right)=3.28(6) ; \delta$ DMEDA $\left(-\mathrm{CH}_{2} \mathrm{CH}_{2} \mathrm{~N}-\right)=$ $2.42(\mathrm{t}): \delta$ DMEDA $\left(-\mathrm{CH}_{2} \mathrm{NMe}_{2}\right)=2.24(\mathrm{~s})$. Fmoc-TMEDA (MeOD): $\delta$ Fmoc (aromatic protons) $=7.20-7.80: \delta$ TMEDA $\left(-\mathrm{CONHCH}_{2}-\right)=3.41$ (q): $\delta$ TMEDA $\left(-\mathrm{CH}_{2} \mathrm{CH}_{2} \mathrm{~N}-\right)=3.36(\mathrm{t}): \delta$ TMEDA $\left(-\mathrm{CH}_{2} \mathrm{NMe}_{3}\right)=3.05$ (s). TMEDA (MeOD): $\delta$ TMEDA $\left(\mathrm{NH}_{2} \mathrm{CH}_{2} \mathrm{CH}_{2}=\right)=2.99(\mathrm{t}): \delta \mathrm{TMEDA}\left(-\mathrm{CH}_{2} \mathrm{CH}_{2} \mathrm{~N}-\right)=3.29(\mathrm{t}) ; \delta$ DMEDA $\left(-\mathrm{CH}_{2} \mathrm{NMe}_{3}\right)=3.08(\mathrm{~s})$

12. The SEC system consisted of a P680 HPLC pump from Dionex Corp. (Sunnyvale. CA). Polvmer sample was detected by a 3angle laser light scattering detector (miniDAWN ${ }^{*}$ Tristar $^{\text {TM }} .30$ $\mathrm{mW}$ GaAs laser. $690 \mathrm{nnm}$ ) and an interferometric refractometer (Optilab DSP ${ }^{\mathrm{TM}}$ ) from Wyatt Technologies (Santa Barbara, CA) DMF was used as an eluent after being filtered through a $0.22 \mu \mathrm{m}$ filter and degassed before use. A Strage ${ }^{*} \mathrm{HR} 3$ column from Waters (Milford. MA) was used.

13. (a) $2 \mathrm{~mL}$ of polyplex solutions containing $5 \mu \mathrm{g}$ of DNA were prepared at various weight ratios ranging from I to 20 . After 30 min incubation. polyplex sizes were measured using a Zetasizer $3000 \mathrm{HS}$ ( $5 \mathrm{~mW}$ HeNe laser. $633 \mathrm{~nm}$. Malvem Instruments, LK). Scattered light was detected at a $90^{\circ}$ angle. (b) Polyplex solutions were prepared in same method as above. Polyplex solutions were diluted to $10 \mathrm{~mL}$ of the final volume prior to measurements. Zetapotential measurements were carried out using a Zetasizer $3000 \mathrm{HS}$ at $25 \% \mathrm{C}$

14. Polyplexes at weight ratios of 5 and 20, were prepared in Hepes buffered saline (HBS, $20 \mathrm{mM}$ Hepes. $150 \mathrm{mM} \mathrm{NaCl} . \mathrm{pH} \mathrm{7.4)}$ ). The samples were collected for assay at various times ranging from the Ist to the 5th day. electrophoresed on a 0.70 (w) agarose gel and then stained in a $I^{0} \cdot a$ (w: v) ethidium bromide solution. 